\title{
SABER ARQUEOLÓGICO Y MEMORIAS LOCALES EN LA COMARCA ANDINA DEL PARALELO 42으. PATAGONIA (ARGENTINA)
}

CAROLINA CRESPO"

\section{RESUMEN}

La arqueología ha sido tradicionalmente investida de autoridad en lo que refiere al conocimiento sobre la forma de vida de los pueblos indígenas en el pasado. Sin embargo y, más allá de esta autoridad que se le adjudica, sus explicaciones no necesariamente son repetidas linealmente por los sujetos. En este trabajo, analizo cómo se interrelacionan las interpretaciones del pasado previo a la "Conquista al Desierto" difundidas por un equipo de arqueólogos que trabaja en la Comarca Andina del Paralelo 42으-Patagonia Argentina- con la de los agentes estatales y pobladores locales, y examino las tensiones, encuentros y/o desvíos que se producen en esa interacción. Demostramos la forma en que procesos político-económicos que se han sucedido en la Patagonia Argentina, discursos antropológicos sobre esa región que dominaron el campo de nuestra disciplina en otras épocas y conflictos interétnicos emergentes en la zona, inciden en la forma variable y compleja en la que se explica el período histórico que investigan y difunden hoy aquellos arqueólogos.

PALABRAS CLAVES: Saber arqueológico, memorias locales, Comarca Andina del Paralelo 42․․

\section{ARCHAEOLOGICAL KNOWLEDGE AND LOCALS MEMORIES AT COMARCA ANDINA PARALELO 42ํ, PATAGONIA (ARGENTINE)}

\begin{abstract}
Archaeology was traditionally considered as an authority on the subject of the indigenous way of live in the past. However, and beyond that authority, their explanations are not necessarilly reproduced literally by others. In this article, I analyze the intersection between interpretations of the past prior "Desert Campaign" spreaded by an archaeological team that works in The Comarca Andina del Paralelo $42^{\circ}$-Argentine Patogonia- with that ones that belongs to state agencies and local people. I examine the tensions, agreements and/or changes produced by this interaction. I demonstrate the way in which political-economics processes in Patagonia Argentina, anthropological discourses about that region which dominates our discipline in others periods and interethnics emergent conflicts in the region, affects the variable and complex form of the interpretations around historical period that research and disseminate those archaeologist nowadays.
\end{abstract}

KEYWORDS: Archaeological knowledge, local memories, Comarca Andina Paralelo 42ㅇ․ 
La mayor parte de los hechos históricos, experiencias pasadas y memorias configuradas en torno a ellos, superan la experiencia inmediata y a una sola generación. En esos casos, ciencias como la historia y la arqueología han sido instrumentos poderosos en la forma en que se han difundido y traspasado aquellas experiencias de largo alcance temporal a la propia historicidad. También en la forma en que este traspaso ha sido realizado. Particularmente cuando se trata de etapas en las que no existe documentación escrita, la arqueología ha sido considerada "la voz autorizada" por excelencia para reconstruir lo sucedido. Esta autoridad que se le atribuye en la construcción de la memoria está presente no sólo en discursos que circulan en la sociedad sino también en la misma jurisprudencia relativa al "patrimonio arqueológico" en Argentina, en la que la ciencia adquiere -a diferencia de otros patrimonios activados- un lugar destacado.

La relevancia del rol que ocupa esta disciplina conduce a una reflexión ya problematizada por numerosos académicos, como lo es la articulación entre praxis intelectual y poder -o entre saber y poder- $y$ sobre el compromiso y la responsabilidad social del científico en la construcción de conocimiento (Gramsci 1963; Berreman 1969; Foucault 1999 y otros). Particularmente en el campo de la antropología y, más aún, en un país como la Argentina en el que se ha excluido y a la vez incluido subordinada y estigmatizadamente a los pueblos indígenas, analizar el papel del discurso antropológico frente a esta situación no representa algo menor. Sin ir más lejos, numerosos autores han destacado el papel político que ha tenido nuestra disciplina, ratificando científicamente, desde diferentes corrientes teórico-metodológicas, políticas de exclusión de diverso tipo (Lenton 2005; Podgorny 2000; Crespo 2008a; entre otros). Sin embargo y más allá de la autoridad esgrimida y el poder conferido al saber científico, las explicaciones que ofrece la arqueología no necesariamente son repetidas linealmente por los sujetos, sino que así como pueden ser reproducidas sin interrogación alguna, también suelen ser reinterpretadas, releídas y "reescritas" a la luz de otras consideraciones. Esto es así, porque el discurso sobre el pasado interactúa con las experiencias y narrativas previas a las que los sujetos sociales han estado expuestos, es decir, con condiciones sociales que abren y/o clausuran posibles lecturas e interpretaciones según la situa- ción y posicionamiento de los sujetos en el tiempo presente.

En este sentido $y$, sin denegar la relevancia que tiene la reconstrucción crítica de la trayectoria teórico-metodológica de las corrientes académicas, el propósito particular de este trabajo es centrarme menos en el discurso arqueológico en sí mismo o intentar establecer efectos lineales que éste produce, que revisar la forma compleja en que se intersecta con las memorias locales ${ }^{1}$. Es decir, a partir de revisar la experiencia de trabajo desarrollada en algunas localidades de la Comarca Andina del paralelo $42^{\circ}$ -de aquí en más Comarca Andina o Comarca-, en Patagonia Argentina, el objetivo de este escrito es analizar varios de los diversos recorridos, puntos de encuentro $\mathrm{y} / \mathrm{o}$ desencuentro, que distintos sectores con intereses divergentes y en desiguales posiciones, trazan con el discurso arqueológico elaborado y difundido sobre el pasado previo a la "Conquista al Desierto"2 en la región patagónica en el contexto actual. Recorridos que, a su vez, repercuten en la reflexión de los mismos académicos en lo que refiere a las orientaciones a seguir en la difusión del conocimiento y las interacciones mantenidas. Asimismo, me motiva demostrar cómo procesos político-económicos e ideológicos que se sucedieron en la Patagonia Argentina, discursos antropológicos sobre esa región que dominaron el campo de nuestra disciplina en otras épocas y conflictos interétnicos emergentes en esta zona comarcal, inciden en la forma variable y compleja en la que se significa, resemantiza y explica la fracción de esta historia indígena que investigan y difunden los arqueólogos que están trabajando en la Comarca.

1 Cabe aclarar que no me detendré aquí a analizar los vínculos gestados con distintos agentes locales (agentes estatales, propietarios de los terrenos donde se emplazan los sitios, partidos políticos, comunidades indígenas, Organismos no Gubernamentales, etc.) a partir de la práctica de investigación y gestión arqueológica. Para un análisis de la dinámica que han revestido estas articulaciones véase Bellelli et al. (2005); Crespo (2006, 2007 y 2008a).

2 "Conquista al Desierto" fue el nombre eufemístico bajo el cual se denominó la campaña militar encabezada hacia 1879 por J. A. Roca en la Patagonia Argentina, que tenía por objeto obtener la soberanía de la Patagonia, hasta esa época de control indígena. Esta campaña militar realizada contra los pueblos indígenas y que supuso el exterminio de gran cantidad de esta población y su posterior subordinación al interior de la nación, finaliza en 1885 y tuvo antecedentes previos. 
Las argumentaciones ensayadas en torno a este pasado dan cuenta menos de historias pasadas que de vinculaciones interétnicas actuales, situaciones y experiencias indígenas, valoraciones hacia estas poblaciones así como de posicionamientos político - ideológicos. Para este examen, el trabajo se ha nutrido de las estrategias metodológicas clásicas de la antropología social, tales como entrevistas abiertas, conversaciones informales y, en especial, observaciones-participantes, junto con el análisis de fuentes secundarias escritas. Entiendo que la perspectiva de la antropología social es enriquecedora para el proceso de investigación y relevante en función de la problemática a indagar.

\section{PROYECTOS Y PROYECCIONES: LA ARQUEOLOGÍA EN LA COMARCA ANDINA}

La Comarca Andina del Paralelo $42^{\circ}$ incluye cinco localidades del Noroeste de la provincia de Chubut -Lago Puelo, El Hoyo, Epuyén, El Maitén y Cholila- y su cabecera, El Bolsón, en el Sudoeste de la provincia de Río Negro. Esta delimitación regional, que todavía está en proceso de unificación, se gesta en los años 90' con la finalidad de oficializar la integración socioeconómica de estas localidades y competir turísticamente con otras zonas aledañas, especialmente, con Esquel y Bariloche que concentran los itinerarios turísticos más frecuentados. Algunas de estas localidades estaban vinculadas previamente entre sí a través de actividades cotidianas como el circuito laboral y comercial de la población.

Hacia el año 1995 un equipo de arqueólogos del Consejo Nacional de Investigaciones Científicas y Tecnológicas -CONICET- inicia una serie de investigaciones en esta región Comarcal, motivados por algunas consultas realizadas por la Subsecretaría -hoy Secretaría- de Cultura de la Provincia de Chubut al Instituto Nacional de Antropología y Pensamiento Latinoamericano -INAPL ${ }^{3}$-. Estas consultas se nucleaban en torno al grado de deterioro que presentaban algunos sitios con arte rupestre de la región y surgían a su vez de ciertas inquietudes de pobladores de la localidad de Cholila, interesados en proteger y gestionar un sitio de arte rupestre denominado "Cerro Pintado".

3 El equipo de arqueólogos pertenece al CONICET y a la Universidad de Buenos Aires y tiene como lugar de trabajo el INAPL.
Las primeras aproximaciones de este equipo a la Comarca consistieron, así, en relevar los sitios arqueológicos con arte rupestre, elaborar un diagnóstico sobre su estado de preservación y confeccionar un plan de acción para su administración y uso adecuado por parte de los visitantes (Podestá et al. 2000). El INAPL y el CONICET fueron las instituciones que financiaron el proyecto mientras la Subsecretaría de Cultura de Chubut otorgó los permisos para el desarrollo de la indagación y aportó en cuestiones de logística ${ }^{4}$. Los resultados de estos estudios fueron volcados, difundidos y distribuidos en la Comarca y fuera de ella a través de un CD ROM realizado por el equipo (Bellelli et al. 1998) así como publicados y presentados en medios académicos.

Hasta esa fecha, no existían indagaciones científicas sobre la forma de vida de las poblaciones que habitaron la zona y estos arqueólogos se dedicaron a llenar ese vacío. El objetivo era -y continúa siéndolodar cuenta de las estrategias de aprovechamiento del bosque y de la zona de ecotono y contextualizar las manifestaciones rupestres (Bellelli et al. 2000 en Ondelj 2004). Paralelamente y, en tanto el interés del equipo se ha centrado no sólo en conocer al "otro del pasado" sino también a aquellos con los que interactúan en el presente, deciden convocar dentro del grupo a una antropóloga social con el ánimo de conocer los significados y usos del pasado en Cholila, y a un antropólogo visual, para relevar en video temáticas vinculadas con la modalidad que reviste la articulación de la práctica arqueológica con la comunidad donde se inserta el equipo.

Las investigaciones que comenzaron en dicha localidad se reiteraron en otras localidades de la Comarca Andina y distintos antropólogos sociales fuimos integrando el equipo en cada caso y configurando diferentes problemáticas de investigación. Por otro lado, y frente a la iniciativa de algunos sectores locales de activar el turismo cultural en la zona de la Comarca exhibiendo sitios con arte rupestre, el equipo pide en el año 2001, un subsidio a la Agencia Nacional de Promoción Científica y Tecnológica, orientado a brindar un marco adecuado para el uso público de los bienes arqueológicos e incorpora al paraje de El Manso, perteneciente a la localidad de El

4 La labor estuvo enmarcada dentro de un programa más amplio denominado "Documentación y Preservación del Arte Rupestre Argentino" diseñado en aquel entonces desde el INAPL. 
Bolsón (Bellelli et al., 2005). Desde entonces, todas estas instituciones -a las que se agregó la Universidad de Buenos Aires y un subsidio de la Fundación Antorchas- han patrocinado estas investigaciones que incluyen a distintos profesionales ${ }^{5}$, que llevan adelante tareas de dimensiones y propósitos variados; esto es, tanto académicas como de transferencia y gestión.

El interés por activar turísticamente estos sitios arqueológicos por parte de algunos sectores de la población fue redireccionando la agenda del equipo. La motivación por la exhibición turística de estos recursos culturales se enmarca en un contexto en el que esta actividad ha cobrado un papel destacado en los programas de desarrollo socioeconómico en el orden internacional y nacional y se dispone de financiamiento para proyectos con este objetivo. En los últimos años, el país fue subdividido en regiones pasibles de ser ofrecidas como atractivos turísticos con una diversidad de ofertas erigidas en su interior, que continúan aún hoy ampliándose ${ }^{6}$. La Patagonia fue especialmente configurada como una "marca" apreciada para ello, en la que ciertas zonas y "productos culturales" son particularmente creados, promovidos y/o difundidos al exterior e interior del país.

En la Comarca Andina, las condiciones impuestas por el contexto económico global junto a la necesidad de hacer frente a la crisis atravesada a nivel provincial y local provocada por el modelo económico neoliberal, fueron impulsando al turismo como alternativa de desarrollo socioeconómico dentro de una economía tradicionalmente centrada en la producción agrícola-ganadera, la fruta fina y la explotación de los recursos forestales (Crespo y Ondelj 2004). La falta de subsidios a proyectos productivos por parte del Estado, de inversión en infraestructura, de promoción del trabajo y el cierre de los ferrocarriles en las décadas protagonizadas por

5 El equipo está conformado por arqueólogos, antropólogos sociales, un antropólogo visual, un historiador, geólogos y una palinóloga.

6 El mapa del país fue dividido en las siguientes regiones turísticas: el "Litoral Argentino" -Chaco, Corrientes, Entre Ríos, Formosa, Misiones y Santa Fé-, "Norte Argentino" Catamarca, Jujuy, Salta, Santiago del Estero y Tucumán-, "Cuyo Argentino" -La Rioja, Mendoza, San Juan y San Luis-, Córdoba, Provincia de Buenos Aires, Ciudad de Buenos Aires y la Patagonia Argentina, que incluye La Pampa, Río Negro, Chubut, Neuquén, Santa Cruz y Tierra del Fuego-. Dentro de estas grandes regiones, aparecen delimitaciones no sólo provinciales sino en función de recursos de interés turísticos. Véase la página web de la Secretaría de Turismo de la Nación: www.sectur.gov.ar la implementación de los programas neoliberales, fueron creando el marco en el que se precarizaron las condiciones de empleo y vida, y aumentaron fuertemente la desocupación y el asistencialismo. La creación de esta nueva delimitación políticoadministrativa y socioeconómica se gestó, de hecho y, como lo apunté al inicio, con el objetivo de aunar localidades que pudiesen, entre otras cosas, competir en términos turísticos. Asimismo, dentro de esta región se están promoviendo distintas propuestas más allá del turismo vinculado con la belleza del paisaje natural, tales como el agroturismo, el turismo de aventura, de deportes extremos y el turismo cultural.

Dentro de este último "rubro", la exhibición del arte rupestre, comienza a interesar a algunos sectores estatales y particulares. La situación socioeconómica descripta, una retórica que impulsa la idea de "desarrollo con identidad" y del "reconocimiento, respeto e 'inclusión' de la diversidad cultural", una legislación provincial -y más tarde nacional- que declaró a los bienes arqueológicos como patrimonio de la misma, la certificación del valor del patrimonio arqueológico por parte de la autoridad científica que trabaja en la zona y antecedentes de otros casos de este tipo en el país, deben haber contribuido en la formulación de estas iniciativas de apertura de los sitios al turismo. Pero además, su alto rendimiento político, su posible relativa rentabilidad económica y su comparativamente baja inversión por parte de los administradores locales, también deben haber incidido en la atención que despierta entre ciertos agentes estatales (Prats 2003).

En la medida en que estas pinturas rupestres constituidas como patrimonio arqueológico provincial y nacional son consideradas una manifestación material única y no renovable realizada por sociedades en el pasado, la propuesta del proyecto ha consistido en elaborar un Plan de Manejo de algunos de estos sitios presentes en la región para organizar la visita de turistas y/o de la comunidad local. El equipo ha relevado un total de 40 sitios con pinturas rupestres en la Comarca Andina7. Muchos de ellos habían

7 No se descarta la posibilidad de seguir encontrando más sitios con arte rupestre en la región. Las pinturas halladas, en su mayoría de coloración amarilla, blanca, roja y verde, se presentan muy desvaídas en aleros rocosos o en paredones y bloques sin reparo. Contienen escasos motivos figurativos y se corresponden con lo que se ha dado en llamar "Estilo de Grecas" (Menghin 1957) en arte parietal y arte mueble, que fuera redefinido por Gradin como "Tendencia abstracta lineal compleja" -TALC-. 
sido previamente registrados por Sánchez Albornoz en 1955. Otros se conocieron más recientemente gracias a pobladores locales. Los estudios realizados en algunos de estos sitios arqueológicos demuestran una ocupación del territorio desde hace por lo menos 2000 años por parte de cazadores-recolectores que aprovecharon diferentes ambientes -estepa, ecotono y bosque-. Su dieta principal se basaba en el consumo del huemul y, en menor medida, guanaco; y recurrían a los recursos vegetales como hongos, plantas medicinales, resinas, maderas y cañas. Utilizaban instrumentos de piedra, recipientes de cerámica, cuentas hechas con valvas de moluscos, placas y hachas de piedra decoradas, pigmentos minerales posiblemente usados en las pinturas, instrumentos en hueso, etc. (Bellelli et al. 2005). Los académicos sugieren que es posible que el bosque haya sido explotado regularmente como parte de la subsistencia o bien que fuera utilizado como zona de tránsito hacia otras regiones ${ }^{8}$. Ciertas coincidencias en lo referente a la estética que presentan las pinturas, la tecnología utilizada en la confección de los instrumentos de piedra y los fechados obtenidos entre estos sitios y otros del bosque y la estepa, así como el hecho de que la materia prima de los materiales hallados proviene de fuentes ubicadas a muchos kilómetros, hacen suponer la existencia en el pasado, de amplias redes de circulación que debieron permitir integrar a esta región con otras.

La elección de los sitios de arte rupestre a exhibir ha estado vinculada con el grado de deterioro que evidencian, su facilidad de acceso, su nivel de visibilidad y de visita ya existente y no organizada -fundamentalmente por parte de pobladores locales, lo cual puede incentivar visitas turísticas no controladas-. Por otra parte, también se considera en la elección el interés de las autoridades y los propietarios de los campos en que se encuentran los sitios como para garantizar un cumplimiento efectivo del Plan de Manejo de los Recursos Arqueológicos (Bellelli et al. 2005:36) y, en los últimos años, la consulta a algunos referentes indígenas y su posición al respecto.

8 Los movimientos de población y la incorporación de nuevos ambientes pudieron deberse al aumento de la densidad de los grupos que habitaban la zona de la estepa en el este. Otra razón pudo haber sido el deterioro de sus habituales recursos de subsistencia (véase Bellelli et al. 2000 en Ondelj 2004)
El Plan de Manejo incluye la producción de conocimiento científico, su difusión y administración planificada, esto es, tomar en consideración la problemática de la preservación del objeto en sí mismo, el relato que acompaña a la visita, así como promover la valoración de ese pasado. En sus palabras, la finalidad es proteger y conservar [este patrimonio planificando la frecuencia y cantidad de visitantes,] y ofrecerles una visión ajustada del pasado de los grupos humanos que vivieron en la región y que fueron los autores de las pinturas rupestres (Bellelli et al. 2005:30). Para ello se requiere no sólo de una investigación científica arqueológica sino también incorporar a otras disciplinas como la geología, la ecología, la botánica, la historia, la antropología sociocultural y a otros profesionales como diseñadores gráficos, etc. Pero además, se estima de vital relevancia la participación de la población en este proceso.

En este sentido, realizar las investigaciones arqueológicas, ya sea para generar conocimiento científico o para proponer una gestión apropiada de estos bienes culturales, involucra interacciones con distintos sectores, instituciones y organismos: agencias provinciales y municipales, otras instituciones estatales locales, propietarios del terreno donde se emplazan los sitios, indígenas, sectores no indígenas, organismos no gubernamentales y/o organismos multilaterales ${ }^{9}$. Lo que sigue a continuación es, ni más ni menos, que el examen de algunas de las tensiones que, durante las interacciones mantenidas con diferentes sujetos en la zona, emergen en las interpretaciones acerca del pasado indígena previo al siglo XIX investigado por el equipo.

9 En el año 2005, el BID aprueba una propuesta de préstamo para "un programa de mejora de la competitividad del sector turismo en Argentina" con el objetivo de "incrementar sostenidamente la generación de divisas proveniente de la actividad turística tanto en el Corredor de los Lagos -Neuquén, Río Negro y Chubut- como en las localidades que se ubican sobre el Río Paraná en la provincia de Misiones, a lo que se denominó Corredor Iguazú-Misiones". El préstamo está orientado a mejorar las instalaciones, equipar y ampliar la oferta turística de los Parques Nacionales y de los municipios insertos en esas regiones. Entre otras ampliaciones, se encuentra la exhibición de parte del patrimonio cultural, histórico y/o arqueológico de cada una de estas áreas. Para más información, véase el "Programa de Mejora de la Competitividad del Sector Turismo" (AR-L 1004). 


\section{VIAJES EN EL TIEMPO Y EL ESPACIO. DE SUJETOS, SUJECIONES Y AGENCIAS}

Los arqueólogos configuran su trabajo en la Comarca alrededor de la noción de "poner en valor" el pasado indígena por ellos estudiado. Esta noción difiere del concepto de "rescatar" lo indígena del olvido que, articulada con la idea de "pérdida de una supuesta cultura étnica" como consecuencia de la "aculturación" gestada por el "contacto con una sociedad superior", congregaba a académicos de otras corrientes teórico-metodológicas, como los de la escuela histórico-cultural en épocas pasadas. La idea de "poner en valor" supone, por el contrario, dar cuenta del valor que pueden tener en la vida actual producciones culturales y formas de vida desarrolladas en el pasado y se condice con la adscripción de los recursos arqueológicos como patrimonio cultural y su pasible exhibición en el mercado. En este sentido, implica no sólo un cambio respecto a la concepción que se ha tenido sobre las poblaciones indígenas en el pasado sino también de su relación con los sujetos que viven en el presente y de la práctica profesional.

A diferencia de lo que ha sido la práctica arqueológica tradicional, estos profesionales, se han preocupado constantemente en interactuar con la población -tanto indígena como no indígena-, conocerla y dar a conocer el conocimiento científico alcanzado. Así, entre los objetivos del proyecto del equipo trazados desde ese entonces, se encuentra no solamente tomar en consideración la conservación del "objeto" en sí, para lo cual se elaboran planes de manejo integrales que permitan su adecuada visita protegiendo a estos bienes de su deterioro. También difundir una historia que permita derribar prejuicios muy internalizados en la zona, en la región y en la nación sobre el pasado aborigen, gestados a partir de políticas económicas y culturales hegemónicas que excluyeron $e$ incluyeron subordinadamente a estos pueblos. Esto implica, entre otras cosas, transferir el conocimiento alcanzado desviándose de las interpretaciones centradas en criterios estéticos, exotizantes, discriminadoras y en los márgenes de la historia así como contextualizando estas producciones culturales en el momento histórico de su realización y uso y mostrando la complejidad de las formas de vida y las relaciones mantenidas en el pasado. También "identificar los valores sociales y simbólicos para los distintos grupos de interés, para lo cual se organizan reuniones y talleres con los diferentes sectores de las comunidades involucradas, con el fin de detectar sus intereses $y$ valores particulares respecto a este patrimonio y para consensuar y coordinar el Plan de Manejo de los Recursos Arqueológicos -PMRA-. Se busca la amplia participación de las organizaciones comunitarias, educativas, gubernamentales, no gubernamentales, las comunidades indígenas y los propietarios de los establecimientos donde están localizados los sitios" (Proyecto ANPCyT 09976 del año 2003-2005). Estos objetivos se han llevado a cabo a través de actividades tales como talleres, charlas, cursos de capacitación, invitaciones al sitio durante las excavaciones, entrevistas en medios de comunicación locales, exposiciones en colegios, diseño y entrega de material fotográfico e informativo, entrega de artículos académicos y libros a las bibliotecas y a pobladores, difusión en revistas de carácter general y del mismo CD ROM, propuestas de implementación de planes de manejo de estos bienes arqueológicos, etc. Pero también, por medio de la incorporación de antropólogos sociales y videos antropológicos que sirven como fuente de difusión, diálogo y conexión permanente con la comunidad. La inclusión de estos estudios socioculturales ha permitido al equipo conocer más cabalmente las relaciones y conflictos actualmente vigentes y la interpretación y valores otorgados al pasado indígena por parte de la población de la zona. Este conocimiento es de vital importancia para poder revisar y modificar la forma en que se transmite el conocimiento académico, el vocabulario a utilizar, los aspectos a enfatizar pero también para reflexionar sobre cómo interrelacionarse con la población.

En líneas generales, la comunicación de las investigaciones arqueológicas supone siempre travesías dentro de la dimensión temporal y espacial. Los arqueólogos organizan sus interpretaciones dentro de una matriz territorial y cronológica, estableciendo las continuidades y variaciones de las formas de vida desarrolladas en la zona durante cada lapso e invitan así, a sus interlocutores locales, a transitar sobre esos itinerarios.

Entre los tópicos que preocupan al equipo transmitir hoy, se encuentra poner en evidencia y ofrecer testimonios científicos acerca de un poblamiento y ocupación más temprana en Patagonia y, en particular, en la región de la Comarca, de la que la historia oficial ha establecido. A pesar de la 
retórica de la igualdad de la que suele nutrirse el proyecto nacional en Argentina, estas localidades de la Comarca Andina constituyeron el origen de la historia de su ocupación y poblamiento como epopeya de los hombres, estableciendo la desigualdad respecto a las mujeres; sedentaria estigmatizando el nomadismo; centralmente blanca excluyendo $e$ incluyendo subordinadamente a los pueblos originarios $y$, finalmente, llevada a cabo individualmente por familias aisladas. Como ya lo ha examinado Ondelj (2004) para el caso de Cholila y tal como se desprende de algunas narrativas históricas oficiales de Lago Puelo y El Bolsón, suele ubicarse a los "primeros pobladores" de la Comarca Andina a fines del Siglo XIX, luego de la "Conquista al Desierto", período en que se inician en forma sedentaria diversas prácticas relacionadas con la producción agrícola-ganadera y se incorporan estos territorios patagónicos bajo la soberanía del Estado nacional ${ }^{10}$. Y es que aquella campaña militar de fines del siglo XIX, constituyó un genocidio que derivó como lo sugiere Lenton en el parte-aguas que ordenó las identidades étnicas y convirtió la antigua diversidad en dicotomía barthiana nosotros-otros (2005: 34).

La percepción de una historia reciente gestada por la población "blanca" en la Comarca se funda, así, en dos representaciones que pueden emerger o no en forma combinada y que se legitiman en los estudios de un académico histórico-cultural, Rodolfo Casamiquela, que tuvo un rol destacado en varias provincias de la Patagonia Argentina. Por un lado, en la idea de que la "Conquista al Desierto" produjo un vaciamiento poblacional en esta zona cordillerana, sea a través del exterminio indígena o de su migración, que dejó a esta geografía "virgen" y "desierta” (Rey y Vidal 1975; A.A.V.V. 1980). Por otro, en una imagen estereotipada del nomadismo que lo vincula con un comportamiento errático, de tránsito, relacionado con la escasez, el azar, el salvajismo, la imprevisibilidad y la falta de ocupación "efectiva" del espacio, lo cual implica la concepción de que, especialmente la región de la Comarca, estaba "desierta" de población indígena en los períodos previos a esta campaña militar.

10 Esta forma de narrar la historia también está presente en los relatos históricos sobre el poblamiento de la provincia de Río Negro que ubican a las poblaciones indígenas fuera de un período histórico y dentro de una suerte de origen mítico. Véase Rey y Vidal (1975) o AAVV (1980).
Acá no era un lugar ocupado por indígenas, acá era a lo sumo un lugar de gualichos donde venían a eso. Yo sigo a Casamiquela y creo que Piltriquitrón quiere decir sacar los bultos más que colgar de las nubes. Creo que esto era un espacio para sacar los gualichos pero acá no había en realidad indígenas. El primer poblador es Motoco Cárdenas ${ }^{11}$. Los primeros pobladores fuimos los blancos, los que nos arriesgamos a estar acá, no los pueblos originarios (Comunicación personal con una psicóloga social de El Bolsón, que trabajó en proyectos vinculados con poblaciones indígenas, Diciembre 2004).

Nuestra región fue hasta no hace mucho tierra de nadie en el más literal sentido de la palabra. (...) Los primeros pobladores, extranjeros y en su inmensa mayoría chilenos, llegaron primero en forma temporaria, yendo y viniendo de un lado al otro de la Cordillera y poco a poco fueron asentándose en forma estable (Traverso y Gamboa, 2003: 15).

La negación de la ocupación aborigen del espacio y los conflictos y discriminaciones hacia los indígenas por parte de sectores con poder, que caracterizan al pasado y presente en la Patagonia y, en particular en esta zona, no obstruyen ni contradicen el interés que algunos administradores locales tienen sobre el patrimonio arqueológico del lugar.

...esto lo había visto desde antes de entrar en turismo y me interesaba (se refiere al CD ROM elaborado por los arqueólogos). Nosotros teníamos que definir productos porque no podía ser que Lago Puelo no los tuviera. Uno era Agroturismo, ya en marcha. Y otro eje que quería definir yo, era el cultural, que existe a nivel internacional. Éste (el patrimonio arqueológico) es un genérico a nivel mundial que tiene un valor inestimable. Esto es una perlita (...) Bueno, yo de indígenas no sé nada. Nunca me interesó el tema. Además siempre se vio al indígena como el que [...] ¿Acá hay comunidades?, ¿no? ${ }^{12}$ (Comunicación Personal, Director de Turismo de Lago Puelo, 2005).

11 Un análisis acerca de la significación compleja que se le ha otorgado a la figura de "Motoco" Cárdenas puede confrontarse en Tozzini (2006).

12 La pregunta final es por demás sugerente pues es de público conocimiento el conflicto territorial existente entre dos comunidades mapuches en Lago Puelo, que están reclamando el título de propiedad comunitario de la tierra, y las agencias estatales locales, que no reconocen su adscripción étnica ni su derecho a la propiedad comunitaria. 
Susceptibles de atracción comercial, las manifestaciones culturales indígenas como el arte rupestre que con anterioridad no revestían gran interés, son entonces reacomodadas y resignificadas en función de la lógica actual del mercado y, en algunas localidades de la Comarca dentro de la provincia de Chubut, se han pedido subsidios al Banco Interamericano de Desarrollo para poder llevar adelante propuestas de exhibición turística de ciertos sitios arqueológicos ${ }^{13}$.

Frente a esta idea de tránsito constante e inestabilidad, que niega la ocupación indígena del espacio, y a otros prejuicios asociados, el equipo de los arqueólogos señala que la probabilidad de ser -entre otras posibilidades- una zona de tránsito no significa la falta de ocupación del lugar. También enfatiza en el grado de conocimiento que tuvieron estas poblaciones del ambiente, su concordancia con modos de vida económicos basados en la caza-recolección que fueron modificándose en el tiempo, la diversidad en las formas de apropiación de los recursos y de uso del espacio, las relaciones y redes de circulación mantenidas con otras poblaciones, el contacto entre ambos lados de la Cordillera de los Andes, etc. Esto es, se ocupan de delinear una imagen más compleja, menos estática y homogénea del pasado de manera de poner en valor a estas sociedades y su producción cultural, y también de concientizar sobre la importancia de cuidar el patrimonio arqueológico, generar una participación activa de la comunidad en ello y promover el compromiso político por parte de los funcionarios, quienes se supone deben otorgar los recursos necesarios para este fin.

Sin lugar a duda, estos propósitos no son fáciles de lograr. La difusión del conocimiento arqueológico a través de charlas informales abiertas a las comunidades, entrevistas en medios masivos de comunicación y visitas a las excavaciones, se enfrenta con tensiones, conflictos e intereses divergentes de larga data -e incluso en ocasiones contrapuestos- acerca de este patrimonio $y$, en especial, de las poblaciones mapuches que viven en la zona. Esas tensiones y problemáticas vigentes salen a la luz en algunos relatos difundidos en los diarios locales, en las interacciones con los

13 En otros trabajos he analizado las contradicciones presentes no sólo en la gestión estatal sino también dentro de este organismo multilateral, en lo referente a la forma de conceptualizar el patrimonio arqueológico (Crespo 2007). funcionarios, en el cauce que sigue el debate con el público que asiste a cada charla o taller ${ }^{14}$ y en las entrevistas o comunicaciones mantenidas con distintos sectores sociales.

Las preguntas y comentarios más frecuentes pueden agruparse en torno a tres problemáticas: aquellas que refieren a las "fronteras étnico-territoriales", las que conllevan a una "exotización de la alteridad" $y$, finalmente, las que aluden a la activación de los bienes arqueológicos como "patrimonio cultural provincial y nacional". En cada caso, ciertas diferencias se invisibilizan mientras otras son objeto de especial tematización, reproduciendo y renovando ciertos consensos -o no- en torno a desigualdades internas ya establecidas.

El primer eje, centrado en establecer determinadas identidades étnicas a manifestaciones culturales muy lejanas en el tiempo, ha sido un tópico que aún hoy está candente en la región por las repercusiones que tiene en materia de derechos indígenas y es uno de los más frecuentes y polémicos en las interacciones mantenidas con los académicos. Entre los derechos indígenas en litigio, me refiero, sobre todo, al profundo conflicto existente por el acceso al título de propiedad de la tierra de varias comunidades mapuches asentadas en estas localidades. Así, no es casual que de las preguntas y relatos se desprenda la asociación de los tehuelches con la confección de las pinturas rupestres, de manera de justificar y fijar mediante estos recursos, nacionalizaciones a los pueblos indígenas en Patagonia. Esto se debe al hecho de que los "territorios de los orígenes ancestrales", más que los lugares de nacimiento, son los que se han utilizado en definitiva en los discursos oficiales, para adscribir, hasta el día de hoy, a los mapuches como poblaciones extranjeras y denegarles derechos.

¿son iguales las pinturas del lado Chileno que las del lado Argentino?

¿son tehuelches esas pinturas?" (Público asistente a la charla que diera el equipo el 16 de Marzo del 2006 en El Hoyo).

14 Las visitas al sitio suelen dirigirse hacia las escuelas. Las charlas, talleres y disertaciones se inscriben dentro del marco de actividades auspiciadas por alguna agencia estatal, en general, vinculada con el turismo y la cultura. En estos casos, asisten en su mayoría, personas relacionadas con la actividad turística, periodistas locales, profesores y alumnos $y$, en menor medida, otros sectores de la localidad y zonas aledañas, entre ellos, algunos indígenas. 
Estas pinturas fueron realizadas por los Tehuelches (Folleto de agroturismo de El Manso referente al arte rupestre denominado "Paredón Lanfré").

Esa asociación, en la que opera en forma subyacente una nacionalización de la etnicidad, ha tenido tanta pregnancia que, en ocasiones -como en esta última transcripción- a pesar de que los arqueólogos no establecen una correlación entre los vestigios hallados y esa identificación étnica, el propietario del terreno donde el equipo ha trabajado, la mantiene. En otras oportunidades y luego de comentarios en los que el equipo intenta desvincular estas correlaciones con una población indígena en particular, aparece de todas formas la necesidad de identificarlos con algún pueblo de pertenencia.

entonces...¿vos estarías diciendo que lo que se vincula con la investigación arqueológica corresponde al pueblo mapuche y no al tehuelche? (Público asistente a la charla que diera el equipo el 28 de Marzo del 2006 en El Hoyo).

Uno nunca puede decir esta pintura es tehuelche o esta es mapuche. Esto es aberrante, pero sí uno puede saber por ejemplo, la figura medio parecida que vimos hoy, que parece un cóndor o un pájaro, si vos te fijas, las capas tehuelches, casi todas las capas tehuelches tenían un choique dibujado, ¿si? Y si te fijas es muy parecido. O sea que lo podes llegar a relacionar. Era un dibujo típicamente tehuelche (Funcionario político de Lago Puelo durante la charla que diera el equipo el 28 de Marzo del 2006 en El Hoyo).

Hace unos 1700 años ya existían pueblos en la región definidos como Patagonienses, predecesores de los tehuelches y poyas en el área precordillerana [...] es probable que una vez culminado el estudio de las cuadrículas excavadas, se cuente con valiosa información acerca del modo de vida de estos hombres (anteriores a los tehuelches y mapuches), que dejaron su impronta en las piedras cercanas ${ }^{15}$ [...] Lo que hoy conocemos como Comarca Andina del Paralelo $42^{\circ}$ era parte del etnoterritorio de los pueblos originarios (desde los patagonienses hasta los tehuelches y mapuches) asentados en la meseta patagónica y en la cordillera ("El Ciudadano", 20

15 Esta frase es reiterada en una nota publicada una semana más tarde, cuando el periodista reconstruye la charla desarrollada el 28 de Marzo del 2006 en El Hoyo por una parte del equipo. de Marzo del 2006. Nota en la que se supone se resume la disertación dada días previos por dos arqueólogas en El Hoyo).

Este último fragmento aparecido en un medio de comunicación local de amplia tirada y distribución gratuita, resulta por demás interesante debido al énfasis que pone en la desadscripción del arte rupestre a ambas culturas -tehuelche y mapuche- $y$ su relación con una supuesta cultura patagoniense, anteriormente construida por los antropólogos ligados a la corriente histórico-cultural. Pues así como la adscripción a una sola cultura -la tehuelche- era una modalidad a través de la cual se chilenizaba a los mapuches, la desadscripción a ambos pueblos no sólo no modifica aquella percepción sino que incluso contribuye a otorgar poca profundidad histórica y discontinuidad a los mapuches, en un contexto en el que éstos y otros indígenas, son obligados a demostrar lo contrario para ser reconocidos en sus demandas.

Ahora bien, en líneas generales, se trata de una problemática o pregunta sobre las que la ciencia buscó dar respuesta y las dio, con mucha certeza y precisión adjudicando la cultura material de tiempos remotos a ciertas identidades étnicas específicas y, desde allí, estableciendo nacionalizaciones sobre las pertenencias étnicas. Sin ir más lejos, Casamiquela (1964, 1980, 2007) ha sido uno de estos académicos que bregó en este sentido. Su discurso se constituyó, para los sectores hegemónicos y gran parte del sentido común circulante, como la estructura de significación desde la cual abordar la cuestión indígena. Muchos comentarios -algunos de los cuales están aquí transcriptos- recogen o rebaten aquellas respuestas que, junto con las de relatos de viajeros de Patagonia ${ }^{16}$, configuraron estructuras ideológicas que contienen consecuencias políticas palpables en la actualidad. Los sospechas acerca de la "veracidad" de automarcaciones mapuches en la región, las denegaciones de títulos de propiedad de las tierras que están siendo reclamados por poblaciones mapuches desde hace varios años en la zona, la forma en que se elabora la historia en ciertas instituciones culturales y libros locales, surgen a partir de la utilización de aquellos textos antropológicos que, al reproducir discursos hegemónicos, conforman algo más que

16 George Musters, por ejemplo, es uno de los viajeros más citados por el público cuando se hacen comentarios sobre el pasado. 
un simple texto. Estas atribuciones identitarias que legitiman la adscripción nacional a identidades étnicas específicas; esto es, los tehuelches como argentinos y los mapuches como chilenos, son discutidas y puestas en duda por parte del equipo. En parte, porque la arqueología empieza a reconocer sus propias limitaciones en el campo del pasado y entonces la demanda se resuelve apelando a la propia incertidumbre eso no lo podemos saber o el registro arqueológico no dice nada respecto a la identidad étnica de quienes lo confeccionaron. Pero sobre todo, porque se parte del supuesto de que los pueblos indígenas sufrieron cambios que tornan difícil extrapolar categorías históricas a tiempos tan lejanos. También porque se presume que las categorías de identificación étnica -tal como lo ha demostrado Nacuzzi (1998)- no necesariamente son producto de autoadscripciones sino de imposiciones de los "blancos". Y, desde ya, por la carga ideológica y las consecuencias que éstas arrastran. En este sentido, el equipo ha tratado de mostrar las relaciones $y$ estrategias implementadas por quienes habitaron y ocuparon la zona y la variabilidad puesta en juego, sin establecer racializaciones, ni nacionalizaciones que surgen con mucha posterioridad dentro de la historia, ni atribuir determinadas identificaciones étnicas a los hallazgos.

Ahora bien, muchos mapuches de la zona también discuten aquella correlación entre etnia y nación y las discriminaciones y desiguales derechos que esto supuso para ellos. Con este propósito, recurren entre otras cosas, a una historia remota. En la discusión que entablan, recuperan una retórica muy presente en los movimientos etnopolíticos mapuches de ambos lados de la Cordillera, basada en el establecimiento de una historia de este pueblo de aproximadamente 10000 años de duración, que trasciende las fronteras nacionales creadas recién a fines de siglo XIX. Así, varios mapuches en El Bolsón como en Lago Puelo, especialmente aquellos que se encuentran en una situación activa de reclamo y lucha frente a derechos objetados, autoadscriben las pinturas rupestres de la región y la cultura material asociada al pueblo mapuche y confrontan aquellas nacionalizaciones étnicas anteriormente señaladas del mapuche como aborigen chileno, que no sólo circulan en discursos oficiales sino que han implicado el no reconocimiento de ciertas potestades, como por ejemplo, el derecho al título comunitario de la tierra.
Para mí los que hicieron eso fueron los Mapuches, porque si uno va relacionando lo que es los ancianos y todos ellos en sus tejidos, en sus artesanías siempre van presentando algún motivo muy similar. Y por ahí, o sea, como ellos ya mueren, o sea de aprovechar los territorios que tenían era como que iban marcando sus puntos y de acuerdo a la pintura que ellos realizaban deben haber hecho alguna ceremonia o algo importante. Porque hay así como las patas del ñandú, o sea, del choique, que bueno, o sea, se relaciona mucho con lo que es la conexión entre el cielo y la tierra. Por ahí, o sea, se puede relacionar...yo, me da la impresión de que lo relacionaba mucho a que alguien llegaba o que alguien se iba. O sea, un nacimiento o la muerte de alguien porque es la conexión entre un mundo y otro (Entrevista a un miembro de la Comunidad Mapuche Cayún, Diciembre 2006).

Otros en cambio, adjudican esas manifestaciones a los indios y entablan, desde allí, relaciones ambivalentes respecto a los indígenas que habitaron la zona antes de fines de siglo XIX ${ }^{17}$. "Indio" es, sin duda, una membresía producida a partir de las relaciones sociales de producción colonial. En este sentido, el término "indio" utilizado para remitir a aquellos que habitaron previamente, con todas las cualificaciones negativas que esto comporta -"bruto", "salvaje", "malos", "rebeldes", "belicosos", "ladrones", "cazadores", "nómades", "negros", "feos", "brujos", "con formas de vida atrasadas"- resulta reveladora. Esta categoría se constituyó en un sistema de referencia que señaló el lugar que debían ocupar estas poblaciones y organizó y legitimó prácticas de violencia armada y de exclusión/inclusión subordinada de la "alteridad étnica". Los relatos no emergen así en un vacío sino en el entramado de fuerzas hegemónicas que, aun cuando aquellas condiciones históricas hayan cambiado, situaciones vividas pasadas y otras no tan pasadas, tienen la suficiente pregnancia como para -parafraseando a Marx- continuar pesando "en el cerebro de los vivos" (1985:107). En este sentido, establecen por

17 Para un análisis más profundo y en detalle sobre las relaciones trazadas por los miembros de comunidades indígenas de El Bolsón y Lago Puelo, véase Crespo (2008a,b). En Catamarca, Pizarro (2006) analiza muchos relatos sobre el pasado entre población no autoreconocida como indígena $\mathrm{o}$, en algunos casos, ambiguamente autodefinida como descendiente de indígenas, que también se organizan a partir de esta categoría "indio". 
un lado una distancia casi irreconciliable cuando, reproduciendo un discurso civilizador, los observan desde el punto de vista cultural.

Porque dicen que los que habían antes eran INdios, indios BRUtos. Lo que pasa es que en eso eran otra gente que no tenían que ver nada con lo de nosotros, ¿no? Eran otra gente que ...como yo le decía, de los indios. ¡Porque hay muchas cosas de ahí que eran de los INDIOS que hacían eso! Y esto es mucho, mucho de ANTES QUE YO ESTABA. Que yo de esa historia no sé nada porque según algunas cositas que preguntaba. Porque como los maestros nos llevaban y yo veía todo. Y llegaba a la casa y les preguntaba a mis viejos. Y bueno, y ellos algunas cosas nos contaban que ellos sabían y otras no. Ellos dicen que eran INdios que hacen eso ${ }^{18}$ (Entrevista a un miembro de la Rinconada de Nahuelpán, Diciembre 2006).

Pero también trazan un acercamiento cuando, cuestionando la retórica oficial del desierto de indígenas en la zona, analizan el pasado desde una dimensión espacial; o bien, cuando señalan ciertos atributos sanguíneos o ejercicios de expropiación y violencia en la que se reconocen con ellos.

Los que anduvieron antes que ellos (se refiere a sus abuelos).... Cuando él vino acá ya había andado gente acá, ya, pero a esos los mataban. Es gente que no podía vivir, tenía que irse para las pampas. Ellos también tenían su raza pero lo que pasa es que ellos, que entraron después recién por acá. Vinieron después acá recién, pero acá ya había andado gente. PEro era gente que vivía y que no hacía que se yo...que vivía de la caza nomás... No era que se poblaban como para decir, vamos a criar animales o vamos a sembrar. Es distinto, ¿vio? Lo otro cuando vinieron los viejos, venían con otra, con otra tradición. De produCIR, sembrar y cosechar y dar vuelta la tierra, ¿no? [...] bueyes, y lo amasaban y los arados y bueno, [...] como más silvestre más bien decir, como más, más, más... con menos pensamiento para cultivar algo, para vivir de otras maneras. Ellos vivían capaz con pura carne nomás, con animales ariscos, porque había MUchos. En esos años había MUchos. ¡Ahora no hay! (Entrevista a un miembro de la Rinconada de Nahuelpán, Diciembre 2006).

18 En todas las entrevistas transcriptas en este artículo, los énfasis realizados por el propio entrevistado han sido marcados con mayúsculas en el texto.
Dicen, gente antigua, que hay Indios. Que hubieron MUchos INdios acá, dicen. Habían ANtes, ANtes. Porque por ahí esas tierras, dicen que esas tierras eran de LOS INDIOS. Dicen que algunos quedaban cuando llegaron los viejos. Algunos... pero vio que después como ya no existían los, los viejos, los indios MÁS viejos, quedaban algunos que...se van, se FUEron, dicen, no sé. Parece que los echaron. No sé, una cosa así. Son indios que había antes, dicen, que escribieron eso, pintaron, para dejar RECUERdos (se refiere a las pinturas rupestres denominadas "Gran Paredón de Azcona"). Porque ellos dicen que se van a otros lados, algunos se mueren. Porque antes había muy poca gente, muy pocos pobladores, dicen. Habían más gente india que... (Entrevista a un miembro de la Rinconada de Nahuelpán, Diciembre 2006).

Y un gringo sacó plata. Sacó una olla que tenían enterrada con plata. Y se fue y cuando volvió, se murió. Sí. Porque es delicado sacar eso. A ESE GRINGO LO CONOCÍ. Iba a mi casa y todo cuando estaba yo. Iba a mi casa. Y él decía que había que sacar ese entierro porque tienen plata los indios (se ríe). (...) Más un blanco menos, menos puede sacarla. UN blanco menos puede sacar eso. Puede ser un indio, sí, puede ser. Porque no les pertenece a ellos. Pertenece a gente india... (Entrevista a un miembro de la Rinconada de Nahuelpán, Diciembre 2006).

Tanto la ocupación indígena del territorio antes del siglo XIX, como la ausencia de un límite nacional e incluso geográfico en la Cordillera y la movilidad allende los Andes, suele unificar la discusión de los mapuches con los que he interactuado en la Comarca. En ese punto, los bienes arqueológicos son el material tangible y visible, entre otros, con el cual testificar esa ocupación de larga data que contradice aquella historia de los "blancos" como "primeros pobladores".

Nosotros lo vemos... yo en el caso mío lo veo como algo sagrado que nosotros tenemos que (...) tratar de preservarla para nuestro futuro, para nuestros pibes, nuestros hijos, para que tengan ellos por ejemplo una noción o nuestros nietos de que antes del blanco acá... para que sepan de que el hombre blanco no fue el que descubrió o el primer poblador de la tierra sino que fueron los nativos directamente los dueños de la tierra (Entrevista 
a un miembro de la Comunidad Mapuche Cayún, Diciembre 2004).

Además de demarcar un origen, los recursos arqueológicos permiten -junto a otros referentessostener una continuidad en la ocupación y explicar los desplazamientos entre uno y otro lado de la Cordillera de los Andes como prácticas de antigua data que han prevalecido hasta fechas no tan lejanas en el tiempo.

Claro, porque como decían, decían ellos, no tiene frontera el país este, los indígenas, como estar en Chile estar en Argentina daba lo mismo.

- ¿Quiénes decían eso?

- Dicen así los que saben más que uno. Sí. $Y$ muchos nos han dicho eso, que lo mismo les daba estar acá, o allá, porque no había límite, len ese momento] y creo que no había este... gendarmería. No estaba nada. Todo libre era (Entrevista a un miembro de la Comunidad Mapuche Cayún, Diciembre 2005).

Estas afirmaciones acerca de la ausencia de fronteras, de redes de circulación e intercambio a través de la cordillera, que están en línea con este propósito de desnaturalizar la vinculación entre identidad étnica y nación, coinciden con aquello difundido por el equipo y suele incluso ser retomado por sectores no indígenas que apoyan las demandas territoriales que éstos están realizando. En varias ocasiones, cuando algunos mapuches de Lago Puelo difunden a través de los medios de comunicación históricos reclamos de la tierra que ocupan, invocan a la autoridad del conocimiento arqueológico para dar cuenta de orígenes, movimientos y permanencias en la ocupación del espacio. Asimismo, en muchos eventos que organizan para difundir la problemática en la que se encuentran, recurren a los afiches elaborados por estos arqueólogos que documentan y describen las pinturas rupestres de la zona.

En estos casos, las memorias activadas sobre aquel período por los mapuches y por quienes los apoyan en sus demandas, se contrapone, por un lado, no sólo a lo que ocurrió sino también a la construcción ideológica de los discursos que se configuraron sobre aquello que pasó y a sucesos y relatos que están aún vigentes. Los recursos arqueológicos en sí mismos no ingresan como objeto de reclamo, pero el relato que éstos permiten expresar, se incorpora en otros reclamos, especialmente, en aquellos articulados en torno a la regularización dominial ${ }^{19}$. Es posible que la forma diferencial en que se resignifica el pasado entre la población mapuche con la que interactué a lo largo de estos años, se vincule con relaciones, conflictos, experiencias y trayectorias históricas particulares que han seguido en estas localidades fronterizas. Esto es, condiciones de existencia diferenciales en el presente que surgen como producto de sus relaciones con itinerarios de proyectos hegemónicos nacionales, provinciales y locales -atravesados por proyectos internacionales-, de movimientos etnopolíticos inmersos en estos órdenes, pero también de la trayectoria propia de cada comunidad o familia y de los recursos en disputa que en cada caso ha mantenido y/o mantiene en la actualidad con los agentes estatales y privados. Estas situaciones producen y estructuran diferenciales sentidos y formas de invocación y selección del pasado.

Ahora bien, el segundo tópico que nuclea comentarios y preguntas muy reiterados en la zona, e incluso difundidos ampliamente a turistas, se vincula con el establecimiento de una radicalización de la "alteridad" a través de su exotización. Estas exotizaciones se relacionan con el tópico anterior, en tanto configuran una frontera con el "otro" y lo estigmatizan. Las mismas incluyen desde interpretaciones místicas acerca de las pinturas y de sus cultores, a interpelaciones como las que siguen a continuación, acerca de la descripción de los materiales empleados para su confección.

¿se usaba orín para hacer los dibujos en las pinturas? ó En Pataguas dicen que las pinturas fueron hechas con sangre [...] (Relatos registrados en conversaciones informales con el equipo en el Marzo del 2005).

Ahora, ¿con qué lo pintaban? ¿Ustedes no saben? ¿Cómo no se borra eso? Algunos dicen que se lastimaban un dedo y con eso... (Entrevista realizada por Lara Bersten a un poblador de El Manso en Diciembre del 2007).

Como ya lo han sostenido Lazzari y Lenton, la interpenetración de los procesos de formación del

19 La participación de la población mapuche de la región en los talleres ofrecidos por los arqueólogos es baja. Particularmente, ciertos miembros de la comunidad Cayún y otros mapuches de Lago Puelo han participado aunque ninguno intervino en las reuniones orientadas a diseñar los planes de manejo del sitio con arte rupestre que se encuentra en la localidad, con excepción de una mapuche que es concejal de la misma. 
Estado y de la Nación implica la generación de dispositivos hegemónicos que inscriben culturalmente a través de agencias administrativas y de la política cotidiana (Corrigan y Sayer, 1985), una metafísica de la nacionalidad, vis á vis una estigmatización étnica (2000:137). Estas inscripciones son recreadas constantemente y se resignifican en nuevos contextos. Más allá de que demarcan una diferencia radical estigmatizada, las estrategias actuales del capital recurren a estos discursos exotizantes como forma de producir negocios y ganancias (Belli y Slavutsky 2005). En muchas ocasiones, resaltar el exotismo de quienes confeccionaron estas producciones culturales es una estrategia utilizada para la atracción del turismo. Prácticas y saberes estigmatizados en otros momentos históricos y considerados exóticos, son visualizados actualmente como fenómenos de interés para las industrias culturales, los sectores privados y el turismo a la par que configuran fronteras internas de "otros" subalternizados.

Finalmente, el tercer eje de debate centrado en la activación de estos bienes como "patrimonio cultural" provincial y nacional, pone en juego confrontaciones hacia los académicos, el Estado y/o los propietarios de los terrenos donde se ubican los sitios. Me refiero a las acusaciones especialmente realizadas de la boca de funcionarios locales ${ }^{20}$ sobre el tráfico ilícito de bienes patrimoniales en el que se recrimina la participación de científicos. También a denuncias de varios pobladores y periodistas de la zona sobre conflictos con propietarios del suelo donde se encuentran algunos sitios, quienes no han permitido el acceso y desarrollo de la investigación arqueológica ni de la gestión de bienes patrimoniales que por ley son de dominio público. Por último, a reclamos a los agentes estatales locales por la falta de atención hacia este patrimonio. Otras veces, los cuestionamientos aparecen bajo la forma de preguntas sobre las fuentes de financiación de la labor arqueológica.

Leído este eje de discusión en conexión con los anteriores examinados, la ausencia de cualquier alusión a los pueblos originarios resulta por demás sugestiva y contrasta incluso con las reflexiones elaboradas en relación a este tema por algunos mapuches de la zona:

20 Estas recriminaciones a los académicos fueron realizadas por funcionarios municipales con los que se fueron gestando algunos conflictos. Sobre dichos conflictos véase Crespo (2007).
Yo creo que así como la provincia reconoce eso, también tendría que reconocer, o sea, reconocer ya el título comunitario y yo creo que ahí sí estaríamos bien hechos como quien dice, si ya reconociste y declaraste de interés provincial $y$ de interés nacional las pinturas rupestres, estaría bueno que también se reconozca por ahí los títulos comunitarios de las comunidades, ¿no? Yo creo que sería un paso importante si se llegara a lograr eso (...) O sea, como que está a medio, ¿no? porque no es solamente que te reconozcan las pinturas y decir que es un patrimonio provincial. Tenes que COMPLETAR eso. Eso es como un círculo que no se cierra. El círculo se va a cerrar cuando se reconozca a las comunidades y se les de el título comunitario, ¿me entendes? (Entrevista a un miembro de la Comunidad Mapuche Cayún, Diciembre 2006).

Cada una de estos tres ejes de debate aquí esbozados denota diferencias en los intereses y valoraciones entre los agentes sociales involucrados. Esto es, las discusiones congregan posturas heterogéneas de sujetos que están desigualmente posicionados. Las poblaciones mapuches de la zona muestran acercamientos y desplazamientos de sentidos asociados a este pasado, tanto respecto a los discursos propagados por los movimientos etnopolíticos como por los arqueólogos que allí trabajan en la actualidad. Sus relatos deben verse como producto de condicionamientos históricos y actuales y posibilidades o márgenes de resistencia o confrontación. Los funcionarios, por su parte, suelen reproducir estereotipos más allá de que los científicos sugieran visiones contrarias. Muchas veces recontextualizan los conocimientos aportados por estos arqueólogos con aquellos ya internalizados y congruentes con los intereses actuales del capital. Entre los medios de comunicación masivos, los sectores vinculados con el turismo y otros sectores, los planteos son divergentes entre sí. En algunos casos, las distancias se acortan y la presencia de los académicos contribuye a romper con ciertos prejuicios. En otros, sucede algo similar a lo ocurrido con los funcionarios. Sirva como ejemplo de estas ambigüedades y contradicciones, una experiencia personal. En Marzo de 2006, me convocaron desde la Secretaría de Cultura y Turismo de El Hoyo para realizar una disertación en la que explicaría públicamente mi propio proyecto de investigación. 
Finalizada la charla, uno de los participantes se acercó para entablar un diálogo. Luego de adular el estudio, agregó un comentario en el que me felicitaba por la fuerza y perseverancia que debía tener como consecuencia de las dificultades que suponía entablar un diálogo con los pueblos indígenas.

Empero, tomen la dirección que tomen, las expresiones ensayadas por nuestros interlocutores no refieren sin más al pasado sino a experiencias presentes de relaciones y conflictos interétnicos pero también partidarios, de clase, profesionales, etc., en las que los mismos académicos nos vemos inmersos $y$ de las que no debemos estar ajenos al momento de proyectar qué decir y hacer y cómo llevar estas acciones a cabo. Los arqueólogos que trabajan en la zona tienden cada vez más a problematizar las interacciones mantenidas y ejercicios de poder presentes en aquello que, en muchos trabajos, se denomina casi sin debate como "la articulación con la comunidad local". Acuerdo con lo apuntado por Ondelj acerca de la necesidad de tener presente que mientras los arqueólogos definen acciones desde su concepción de 'registro arqueológico', que connota la idea de 'conservación' y atribuyen ciertos significados a la 'evidencia' en función de los marcos explicativos científicos, quienes conviven con esas producciones elaboradas en el pasado, incorporan y redefinen sus significados de acuerdo a la dinámica de las relaciones cotidianas. Luego, que esas relaciones cotidianas sólo muestran sus sentidos en el contexto histórico más amplio que no es diferente al que condiciona también la producción de conocimiento científico sobre el 'registro arqueológico', el 'patrimonio cultural', los 'usos del pasado', etc. (2004:81).

\section{CONSIDERACIONES FINALES}

Durante mucho tiempo, los arqueólogos desestimaron el hecho de que la historia también es producida por fuera de la academia e incluso se han desentendido de la forma en que sus prácticas y discursos se intersectan con prácticas y discursos de otros sujetos e instituciones y están condicionados por contextos sociales específicos (Ayala 2003). La "lejanía temporal" sobre la que se funda -en este caso- la investigación arqueológica, no torna a este pasado menos problemático ni conflictivo en su significación ni en su gestión. Por el contrario y, como se señaló a lo largo de este escrito, la incidencia que tiene el discurso y la práctica de los arqueólogos sigue caminos disímiles y a veces genera incluso fuertes tensiones.

La premisa que me embarcó en este trabajo fue examinar cómo se ponen en juego en estas prácticas del recuerdo, ejercicios de poder y condicionamientos que responden a coyunturas presentes e históricas. La complejidad y variabilidad en los sentidos otorgados a las expresiones y bienes realizados por poblaciones indígenas antes de fines del siglo XIX, muestran cómo los distintos sectores, desde desiguales condiciones, se posicionan ideológicamente en la actualidad frente a prácticas y discursos que sobre la memoria indígena se han elaborado sea desde las agencias estatales, multilaterales y los académicos en distintos períodos; pero también y sobre todo, frente a la situaciones y conflictos vividos en el presente. Las confrontaciones y ejes de discusión que se instalan en el ámbito local son producto de la trama de relaciones de fuerza trazada hasta la fecha y conforman asimismo parte de los dispositivos productores que van tejiendo esa urdimbre de poder. En este sentido, las trayectorias recorridas sobre el pasado indígena por parte de cada sector, incluidos los mismos académicos, van abriendo y/o clausurando relaciones y posibilidades. Dado el lugar que ocupa la ciencia en nuestra sociedad, su discurso se considera, en ocasiones, desafiante; en otras, un baluarte de apoyo de inestimable valor; o bien, ambas cosas simultáneamente.

Las diferencias en las memorias activadas deben ser pensadas no como una abstracción sino situadas en sus condiciones sociales de producción. Son el resultado de luchas desiguales entre grupos humanos por el control de "sí mismos" y de los "otros", de ciertas estructuras objetivas de poder y resultan tanto estructurantes de las prácticas sociales como productoras del mundo social pasado, presente y futuro.

Pero además, los desvíos y acercamientos establecidos son indicativos de distancias y acercamientos, oposiciones y consentimientos respecto del discurso antropológico -más específicamente arqueológico- tradicional y reciente, según el caso. Esos relatos y prácticas no se construyen en forma aislada sino en una red de experiencias y discursos que tienen una historia previa a la que viajeros, militares, sistemas educativos, libros de textos, 
programas de agentes estatales e internacionales, privados, medios de comunicación, movimientos sociales, literatos, etc., pero también antropólogos y arqueólogos, han abonado. La producción de saber antropológico de la escuela histórico-cultural en Patagonia Argentina -hoy discutidas por muchos mapuches y también en ciertos aspectos, desde otro lugar, por los arqueólogos que trabajan en la Comarca-, han dejado mucho más que huellas en estas controversias.

Las interpretaciones locales sobre el presente y el pasado y los condicionamientos y conflictos actuales, son el combustible sobre el que continuamente reflexionan los arqueólogos para pensar cómo articularse con la sociedad con la que interactúan. La producción de conocimiento académico y la práctica profesional se mueve sobre la base de agendas que pueden adecuarse y/o cuestionar o redireccionar en forma paralela, políticas e intereses gestados en ámbitos no estrictamente científicos. El escenario local fue redireccionando el quehacer de los arqueólogos. El incremento del uso turístico de bienes arqueológicos, normativas existentes respecto al "patrimonio arqueológico", serios conflictos territoriales, disputas partidarias locales, así como cuestionamientos de algunos sectores sociales, han generado ciertos cambios en su labor profesional, en su papel como mediador cultural y no pocas consideraciones respecto a qué decir-hacer, cómo hacerlo, frente a quienes, para qué y para quienes. Las reflexiones son continuas y las respuestas nunca definitivas sino siempre dinámicas.

\section{BIBLIOGRAFÍA}

A.A.V.V. 1980. Río Negro. Pasado y Presente. Chrismar Ediciones, Río Negro.

AYALA, P. 2003. Arqueología y Sociedad: el caso de las comunidades indígenas en Chile. Revista Werken № 4: 59-73.

BERREMAN, G. 1969. ¿Está viva la antropología? La responsabilidad social en la antropología social. América Indígena vol. XXIX № 3.

BELLELLI, C.; M. PODESTÁ; P. FERNÁNDEZ; V. SCHEINSOHN y D. SÁNCHEZ. 1998. Imágenes para el futuro. Arte rupestre patagónico: su registro y preservación en la Comarca Andina del Paralelo $42^{\circ}$. Disco compacto.

BELLELLI, C.; V. SCHEINSOHN; M. PODESTÁ; M. CARBALLIDO; P. FERNÁNDEZ y S. CARACOTCHE. 2005. Arqueología, arte rupestre y turismo. Comarca Andina del Paralelo 42, Argentina. Estudios y Perspectivas en Turismo Volumen 14: 22-50

BELLI, E. y R. SLAVUTSKY. 2005. Patrimonio: territorio, objetos, símbolos, personas. ¿Cuál es la disputa?. Mundo de antes № 4: 13-17.

CASAMIQUELA, R. 1964. Estudio del nillatún y la religión araucana. Cuadernos del Sur. Instituto de Humanidades. Universidad Nacional de Bahía Blanca, Bahía Blanca.

CASAMIQUELA, R. 1980. Panorama etnológico de la Patagonia. Río Negro pasado y presente. Ediciones Chrismar, Río Negro.

CASAMIQUELA, R. 2007. Rodolfo Casamiquela "racista anti-mapuche" o la verdadera antigüedad de los mapuches en la Argentina. Biblioteca Popular Agustín Alvarez, Trelew.

CRESPO, C. 2006. Entre el 'deber' y el 'derecho': patrimonio arqueológico y obligaciones mutuas en Patagonia Argentina. Intersecciones en Antropología 7: 63-76.

CRESPO, C. 2007. Políticas de Desarrollo, patrimonio arqueológico y turismo en Lago Puelo, Comarca Andina del Paralelo 42 , Patagonia Argentina. VII Reunión de Antropología del Mercosur. Porto Alegre, Brasil. Ms.

CRESPO, C. 2008a. Políticas de la memoria, procesos de patrimonialización de los recursos arqueológicos y construcción identitaria entre los Mapuches de la Rinconada de Nahuelpán en Río Negro. Tesis doctoral en Filosofía y Letras, Universidad de Buenos Aires. MS.

CRESPO, C. 2008b. Arqueología y Territorio: Miradas actuales sobre pasados lejanos entre los Mapuches de Lago Puelo, Chubut. X Congreso de la Asociación Latinoamericana de Antropología Biológica, La Plata, Argentina. Ms.

CRESPO, C. y M. ONDELJ. 2004. Pinturas en las rocas, Turismo y Patrimonio en la Patagonia Argentina. Algunas consideraciones desde la antropología. En: Antropología de la cultura y el Patrimonio. Diversidad y Desigualdad en los procesos culturales contemporáneos, Rotman, M. (Ed.). Ferreyra Editor, Córdoba.

FOUCAULT, M. 1999. Historia de la sexualidad 1. La voluntad de saber. Siglo XXI, México.

GRAMSCI, A. 1963. La formación de los intelectuales. En: La formación de los intelectuales. Editorial Grijalbo, Buenos Aires.

LAZZARI, A. y D. LENTON. 2000. Etnología y nación: facetas del concepto de Araucanización. Avá. Revista de Antropología №1:125-140.

LENTON, D. 2005. De centauros a protegidos. La construcción de la política indigenista argentina desde los debates parlamentarios (1880-1970). Tesis de Doctorado. Facultad de Filosofía y Letras, Universidad de Buenos Aires. MS. 
MARX, K. 1985. El Dieciocho brumario de Luis Bonaparte. El Manifiesto Comunista y otros ensayos. Editorial Sarpe, España.

MENGHÍN, O. 1957. Estilos del arte rupestre de Patagonia. Acta Prehistórica I: 57-87.

NACUZZI, L. 1998. Identidades impuestas. Tehuelches, aucas y pampas en el norte de la Patagonia. Sociedad Argentina de Antropología, Buenos Aires.

ONDELJ, M. 2004. Memoria Social en la Patagonia Argentina. El pasado en el presente de Cholila. Tesis de Licenciatura en Ciencias Antropológicas, Facultad de Filosofía y Letras, Universidad de Buenos Aires. MS.

PIZARRO, C. 2006. Somos indios civilizados. La (in)visibilización de la identidad aborigen en Catamarca. Anuario de Estudios en Antropología Social 3: 179-195.

PODESTÁ, M.; C. BELLELLI; P. FERNÁNDEZ; M. CARBALLIDO y M. PANIQUELLI. 2000. Arte rupestre de la comarca Andina del Paralelo $42^{\circ}$. Un caso de análisis regional para el manejo de recursos culturales. En: Arte en las rocas. Arte rupestre, menhires y piedras de colores en Argentina. Sociedad Argentina de Antropología, Buenos Aires.

PODGORNY, I. 2000. El argentino despertar de las Faunas y de las Gentes Prehistóricas. Coleccionistas, estudiosos, museos y universidad en la creación del patrimonio paleontológico y arqueológico nacional (1875-1913). Eudeba, Buenos Aires.

PRATS, L. 2003. Patrimonio + turismo = ¿desarrollo? Pasos. Revista de Turismo y Patrimonio Cultural 1 (2): 127-136.

REY, H. D. y L. VIDAL (Cord. General) 1975. Historia de Río Negro. Editorial Río Negro, General Roca.

TOZZINI, M. A. 2006. Hilvanando opuestos. Lecturas identitarias a partir de la conformación de una comunidad mapuche en Lago Puelo, Provincia de Chubut. Avá. Revista de Antropología № 10: 47-65.

TRAVERSO y GAMBOA, J. 2003. Lago Puelo. Un rincón de la Patria. Buenos Aires, Gladius. 